\title{
Experts point to concerning disparities within MD-PhD programs
}

A close look at the elite physician-scientist programs in the US has sparked questions about the retention of women and minorities in such programs.

Many students in $\mathrm{MD}-\mathrm{PhD}$ programs receive financial assistance from the government's Medical Scientist Training Program (MSTP), which received more than $\$ 40$ million from the US National Institutes of Health last year alone. Although these courses enroll only around $3 \%$ of US medical graduates, they have been seen as an important aspect of the American educational system since their founding in the 1960s.

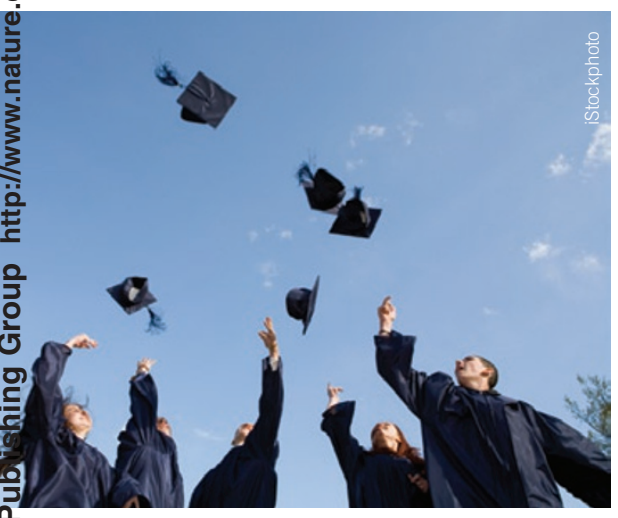

Graduation day: Not everyone gets there
Dorothy Andriole of the Washington University School of Medicine in St. Louis and her colleagues collated information from nearly 80,000 US medical graduates, including almost 2,000 joint-degree graduates. The group's report, released in September, details among other things that only $30 \%$ of those graduating from $\mathrm{MD}-\mathrm{PhD}$ programs were female, compared with $46 \%$ of those graduating from regular MD programs (J. Am. Med. Assoc. 300, 1165-1173; 2008). And whereas around three-quarters of the men who entered the dual-degree programs completed them, only two-thirds of the women who matriculated into these programs finished them.

"The real concern on my part is that whereas women are joining these programs, they do not seem to be staying the course," says Leon Rosenberg of Princeton University. "For whatever reason, we are not retaining women in these programs at the numbers we need to."

The new study also found that only $7.4 \%$ of those graduating from $\mathrm{MD}-\mathrm{PhD}$ programs were from under-represented minorities, such as black and Hispanic groups, compared with $13 \%$ for standard medical degrees.

"I do think there is cause for concern" in the lack of diversity among MD-PhD trainees, says Greg Barsh, head of Stanford's MSTP and a former MD-PhD student himself. "At my program, we work very hard to promote diversity. I think we've been successful, but must continue to work in an affirmative and proactive manner."

Uncertainties also remain over whether the career intentions of students entering $\mathrm{MD}-\mathrm{PhD}$ programs match actual outcomes, and whether MSTP support is producing scientific innovation that would not otherwise have come about.

These questions may be answered in the near future. David Engman, director of the MSTP division at Northwestern University and chair of the Association of American Medical Colleges' MD-PhD Section, told Nature Medicine that a system is currently being developed to track outcomes from these programs.

"We have just completed a study of more than 2,000 current MD-PhD students, 1,100 $\mathrm{MD}-\mathrm{PhD}$ graduates still in postgraduate training and 2,900 $\mathrm{MD}-\mathrm{PhD}$ graduates who have completed training," says Engman. $\mathrm{He}$ adds that the results show that $16 \%$ have entered private practice, whereas $68 \%$ have careers in academia and $8 \%$ work in the biotech or pharmaceutical industries.

Daniel Cressey, London

\section{Success of blood-sugar monitors puts artificial pancreas in reach}

When Aaron Kowalski was diagnosed with diabetes 24 years ago, the young woman in her twenties who lived across the street from his family had already gone blind from the disease. People with diabetes had to rely on a crude test-urine sugar levels - to gauge their control of the condition.

Today, diabetes management has improved dramatically. But for advocates such as Kowalski, 37, a senior scientist at the Juvenile Diabetes Research Foundation (JDRF) in New York, it has not fully arrived in the twenty-first century. Nor will it, he says, until diabetics can wear a cell phonesized device that continuously monitors their blood sugar and doses them with appropriate amounts of insulin in response.

Such a system — essentially, an artificial pancreas - is moving tantalizingly closer to reality, supported by promising results from a JDRF-funded trial involving more than 300 subjects aged 8 to 72 ( $N$. Engl. J. Med., doi:10.1056/nejmoa0805017; 2008). The treatment group wore a continuous glucose monitoring (CGM) device, which relies on a small sensor inserted just beneath the skin that sets off an alarm when blood sugar levels get too high or too low, alerting the wearer to adjust his or her insulin intake. The control group, meanwhile, used standard, intermittent testing of their blood with finger-pricking devices to guide their self-administration of insulin.

In the six-month trial a key measure of average blood sugar levels dropped half a percent in adults using CGM devices; in their control counterparts the measure remained essentially the same. Although that reduction may sound paltry, it is, in fact, a huge improvement: a single percentage point drop reduces the risk of long-term complications by about 40\% (N. Engl. J. Med. 329, 977-986; 1993).

"This is a huge step forward," says Kowalski, who himself has been wearing a CGM device for two years and heads the JDRF's Artificial Pancreas Project. "We have lots of anecdotal experience suggesting that this technology is really transformational. What this paper did is validate what we heard."

"This paper says we should keep that development work going on the artificial pancreas," says Richard Bergenstal, who was not involved with the study but serves as vice president for medicine and science at the American Diabetes Association.

Beyond a CGM component, an artificial pancreas would also include a subcutaneous insulin pump-a technology that has been around for decades and is used by roughly $30 \%$ of diabetics. What's now in development is the third component: a miniature computer containing algorithms that translate the continuous readings from CGMs into commands for the insulin pump, telling it how much insulin to dose out and when.

JDRF is currently funding a seven-site study of a prototype artificial pancreas employing all three elements. On the basis of the preliminary results, says Kowalski, "it's incredibly likely we're going to see another major leap forward."

Meredith Wadman, Washington, DC 